\title{
Evaluation of a community pharmacy delivered oral contraception service
}

\author{
Judith Parsons, ${ }^{1}$ Christine Adams, ${ }^{2}$ Najia Aziz, ${ }^{3}$ Jo Holmes, ${ }^{4}$ Ruhi Jawad, ${ }^{5}$ \\ Cate Whittlesea ${ }^{6}$
}

${ }^{1}$ Programme Manager for Contraception, Primary Care Directorate, Southwark Primary Care Trust, London, UK

${ }^{2}$ Pharmacist, Primary Care Directorate, Southwark Primary Care Trust, London, UK

${ }^{3}$ Specialist Trainee in Community Sexual and Reproductive Healthcare, Community Sexual and Reproductive Health, Guys and St Thomas NHS Foundation Trust, London, UK

${ }^{4}$ Head of Primary Care Delivery and Development, Primary Care Directorate, Southwark Primary Care Trust, London, UK

${ }^{5}$ Consultant in Sexual and Reproductive Health, Community Sexual and Reproductive Health Guys and St Thomas NHS Foundation Trust, London, UK ${ }^{6}$ Senior Lecturer Pharmacy Practice, King's College London, King's Health Partners, Pharmaceutical Science Clinical Academic Group, Institute of Pharmaceutical Science, London, UK

\section{Correspondence to}

Dr Cate Whittlesea,

King's College London, Franklin-Wilkins Building, 150 Stamford Street, London SE1 9NH, UK; cate.whittlesea@kcl.ac.uk

Received 17 January 2012 Accepted 12 July 2012 Published Online First 25 August 2012
To cite: Parsons J, Adams C, Aziz N, et al. Journal of Family Planning and Reproductive Health Care 2013;39:97-101.

\begin{abstract}
Introduction In the UK half of all pregnancies are unplanned and half of teenage pregnancies terminated. Southwark and Lambeth have the highest teenage conception rates in London. In 2009, many teenage pregnancies in Southwark led to terminations. A contraception service was established where qualified pharmacists supplied oral contraception (OC) using a patient group direction (PGD). This service evaluation aimed to assess this service delivered in five community pharmacies.
\end{abstract}

Methods Monthly data were submitted by each pharmacy to the Primary Care Trust on consultations, pills supplied, initial or subsequent supply and client referral. For specified periods consultation time was collected and a clinical notes audit undertaken. Client satisfaction was determined using a structured questionnaire returned to the pharmacy. Mystery shoppers were employed to assess the service.

Results A total of 741 consultations were undertaken by seven pharmacists at five community pharmacies (October 2009-June 2011) with many $(45.5 \%)$ occurring following emergency contraception supply. The mean consultation time was 19 minutes. Combined OC was most commonly supplied with nearly half $(46.1 \%)$ of initial supplies to first-time pill users. Most consultations (92.2\%) were with women aged under 30 years, with $22.5 \%$ aged under 20. Most consultations were with black or black British clients. Of the 99 women who completed the satisfaction questionnaires, most clients were very satisfied or satisfied with the service and felt comfortable talking to the pharmacist about contraception.

Conclusions Trained pharmacists were clinically competent and provided OC in community pharmacy according to a PGD. This service was accessed by the target population; young women using emergency hormonal contraception who had not previously used OC. Clients were largely very satisfied with the service.

\section{KEY MESSAGE POINTS}

Trained community pharmacists provided a clinically appropriate oral contraceptive service under a patient group direction.

- Community pharmacy is a feasible site from which to provide oral contraception (OC) and was used largely by young women accessing emergency hormonal contraception. Nearly half the clients were first-time pill users.

- Clients valued the community pharmacy $O C$ service and would recommend it.

\section{INTRODUCTION}

Half of UK pregnancies are unplanned ${ }^{1}$ and around half of teenage pregnancies are terminated. ${ }^{2}$ Having children in adolescence is associated with poor maternal and child social, economic and health outcomes $^{3}$ incurring National Health Service costs estimated at $£ 63$ million per year. ${ }^{4}$ Improving access to contraception services can contribute to lowering teenage conception rates $^{3}$ and reducing unintended pregnancies. ${ }^{5}$ The Government has released policy on preventing unintended teenage pregnancies, ${ }^{6}$ guidance on long-acting reversible contraception (LARC), ${ }^{7}$ and recently focused on LARC promotion.

Consistent and long opening hours, anonymity, no appointments nor long waiting times mean community pharmacy has a key role in health service provision. Since 2001, emergency hormonal contraception (EHC) has been available from UK community pharmacies, increasing contraceptive access ${ }^{8}$ and potentially benefiting women by provision of longerterm contraceptive advice. ${ }^{9}$ 
Southwark and Lambeth have the highest teenage conception rates in London. ${ }^{2}$ In 2009, most teenage pregnancies in Southwark (66\%) and Lambeth (60\%) led to terminations. In 2005, approximately 16693 young women aged 15-24 years were resident in Southwark and Lambeth. ${ }^{10}$ The largest ethnic groups are white or white British (Southwark, 66\%; Lambeth $68 \%)$ and black or black British (17\%). ${ }^{11}$ In Southwark conception rates are higher in black Caribbean, black African and mixed race groups, with a higher proportion of black African teenage pregnancies (74\%) being terminated. ${ }^{10}$ In South East London $33 \%$ of all women aged under 25 years have had a repeat termination. ${ }^{10}$

In 2008-2009, 7441 EHC consultations occurred in Southwark community pharmacies. Evaluations indicate that EHC access is more rapid in pharmacy than in sexual and reproductive health (SRH) services with similar clinical outcomes. ${ }^{12}$ Clients who attend a pharmacy for chlamydia testing value the speed, convenience and pharmacists' non-judgemental attitude, ${ }^{13}$ although privacy at the counter can be suboptimal ${ }^{12} 13$ and trained pharmacists not always available. ${ }^{13}$ Providing EHC clients with immediate access to oral contraception (OC) could contribute to reducing unintended pregnancies.

In 2009, Southwark and Lambeth Primary Care Trusts (PCTs) developed a patient group direction (PGD) for community pharmacists to supply OC without prescription. Qualified pharmacists, who had undertaken additional training, as described below, would provide initial and subsequent supplies of combined oral contraceptives (COCs) and progestogenonly pills (POPs) to women over 16 years who fulfilled particular criteria. The PGD enabled pharmacists to provide traditional or quick-starting of the pill. A 15 credit MSc module in Oral Hormonal Contraceptive Services was developed by the Department of Pharmacy and Florence Nightingale School of Nursing and Midwifery, King's College London. This involved 5 days of tutorials including clinical assessment skills, completion of three Centre for Pharmacy Postgraduate Education (CPPE) distance learning packages (Contraception, Safeguarding Children and Emergency Contraception) and a clinical placement (20 hours) in SRH services under supervision (doctor/nurse mentor). Assessment was through a practice-based portfolio.

This service evaluation aimed to evaluate the OC service delivered by community pharmacists in Lambeth and Southwark.

\section{METHODS}

Expressions of interest in providing OC were invited from community pharmacies in March 2009. Pharmacies were selected based on sexual health service provision, high EHC supply rates and location in a high teenage pregnancy area. They were required to have a private consultation room. Two pharmacists from each pharmacy were recruited for training to ensure service cover. Sixteen pharmacists completed the OC service module (7 September 2009; 4 March 2011; 5 October 2011).

The service was advertised by posters displayed in the windows and at the counter of each pharmacy. Posters and cards advertising the service were sent to targeted local youth venues and sexual health services for display.

Participating pharmacies submitted monthly data to the PCT on consultations, pills supplied, initial or subsequent (client returning for further pill) supply and client referral. This evaluation uses data from October 2009 to June 2011. Consultation time was collected by the first three pharmacies offering the service (Pharmacies A, B and C, October 2009-September 2010). All the data were analysed using Microsoft Excel (2003). All studies were considered audit or service evaluation and therefore did not require ethical approval.

In August 2010, a clinical notes audit was conducted by a Southwark SRH specialty doctor at Pharmacy A (where most consultations occurred). One hundred and eighty randomly selected client consultations undertaken between October 2009 and August 2010 were audited against the criteria set out in the PGD. This audit assessed PGD adherence and clinical appropriateness of pill supply or referral.

A self-completed anonymous structured questionnaire adapted from the PCT chlamydia testing questionnaire $^{13}$ was used to evaluate client satisfaction. Pharmacists at the first three pharmacies offering the service were requested to give the questionnaire to all clients during consultations between November 2009 and June 2010. Questionnaires were returned to the pharmacist for collection by the PCT.

In April-May 2010, mystery shopper evaluations were conducted at Pharmacies A, B and C using seven trained women (aged 16-18 years). Standard methodology was adapted for use. ${ }^{14}$ Mystery shoppers completed a structured questionnaire including Likert scales immediately after each visit scoring their experience.

\section{RESULTS}

\section{Service provision}

OC was provided in five pharmacies (Table 1). Due to pharmacists not completing training or trained pharmacists moving pharmacy, Pharmacies B and D had only one trained pharmacist and Pharmacy C one part-time trained pharmacist. Differences in mean average consultations per month of service ranged from 30.5 (Pharmacy A) to 1.1 (Pharmacy B).

\section{Consultations}

A total of 741 consultations were undertaken (Table 2). Most $(69.1 \%, n=512)$ resulted in an initial supply of contraception. COC was most commonly 
Table 1 Number of contraceptive consultations in all pharmacies between October 2009 and June $2011(n=741)$

\begin{tabular}{llllll}
\hline Parameter & Pharmacy A & Pharmacy B & Pharmacy C & Pharmacy D & Pharmacy E \\
\hline Type of pharmacy & Small multiple & Independent & Independent & Independent & Independent \\
Trained pharmacists $(n)$ & 2 & 1 & 1 (part time) & 1 & J \\
Period of service & October 2009 to & October 2009 to & January 2010 to & January 2011 to & June 2011 to \\
& present & September 2010 & June 2010 & present & 63 \\
Consultations $(n)$ & 641 & 13 & 18 & 63 & 6 \\
\hline
\end{tabular}

supplied (724 packs), with Microgynon ${ }^{\circledR} 30$ constituting $65.1 \%(n=471)$. POP was less commonly supplied (196 packs), with Cerazette ${ }^{\circledR}$ constituting 64.3\% $(n=126)$ of POPs supplied. Nearly half $(46.1 \%$, $n=236$ ) of all initial supplies were to first-time pill users. A general referral was defined as referral to general practice or SRH services for a client requesting OC but not fulfilling the PGD criteria, a client requesting COC or POP not covered by the PGD or where the pharmacist had concerns about supply.

Subsequent pill supplies were only provided in Pharmacies A and D. In the first 6 months of service, Pharmacy D provided a higher proportion of subsequent supplies than Pharmacy A (a two sample $t$-test $p=0.01$ ).

\section{Client referrals}

Client referral into the service was obtained for 602 $(81.2 \%)$ consultations. Many were requested directly by clients $(40.0 \%, n=241)$ or through discussion during EHC provision $(45.5 \% n=274)$. General practice staff, other pharmacies or SRH services made 75 $(12.5 \%)$ referrals. Conversation between the pharmacist and client when the clients attended for a reason other than EHC resulted in 12 (2.1\%) consultations.

\section{Demographic data of clients}

Age was collected for $98.8 \%(n=732)$, postcode for $98.0 \%(n=726)$ and ethnicity for $80.8 \%(n=599)$ of

Table 2 Outcomes of contraceptive consultations in all pharmacies between October 2009 and June $2011(n=741)$

\begin{tabular}{lll}
\hline Outcome of consultation & $\begin{array}{l}\text { Number } \\
(\boldsymbol{n})\end{array}$ & $\begin{array}{l}\text { Percentage } \\
(\%)\end{array}$ \\
\hline $\begin{array}{l}\text { Consultations resulting in initial supply of OC } \\
\text { to established pill user* }\end{array}$ & 276 & 37.2 \\
$\begin{array}{l}\text { Consultations resulting in initial supply of OC } \\
\text { to first-time pill usert }\end{array}$ & 236 & 31.8 \\
$\begin{array}{l}\text { Consultations resulting in repeat supply of OC } \\
\text { Consultations resulting in general referral }\end{array}$ & 181 & 24.4 \\
$\begin{array}{l}\text { Consultations resulting in LARC referral } \\
\text { Consultations resulting in under-16 years }\end{array}$ & 9 & 4.9 \\
referral & 3 & 0.4
\end{tabular}

*Established pill user describes a client who reports having previously been prescribed OC. Initial supply indicates that it is the first supply of OCPS prescribed from the participating pharmacy.

†First-time pill user describes a client who reports not having previously been prescribed OC.

$\ddagger$ Repeat supply describes a supply of OC given to a client who has previously been prescribed it at the participating pharmacy.

LARC, long-acting reversible contraception; OC, oral contraception. consultations. Consultations mainly occurred with Southwark or Lambeth residents $(97.1 \%, n=705)$. Clients aged $>40$ years constituted 1.9\% $(n=14)$ of consultations, $5.9 \%(n=43)$ of consultations were with those aged $31-40$ years, $26.1 \%(n=191) 25-30$, $43.6 \% \quad(n=319) \quad 20-24 \quad$ and $22.5 \% \quad(n=165)$ $\leq 19$ years. The largest proportion of consultations $(54.1 \%, n=324)$ were with black or black British clients; $32.2 \% \quad(n=193)$ with white clients; $5.8 \%$ $(n=35)$ with clients from mixed ethnic groups; $3.5 \%(n=21)$ with Asian or British Asian clients; and $4.3 \%(n=23)$ with Chinese clients or those from another ethnic group.

\section{Consultation time}

Consultation time was collected for 97.2\% $(n=384)$ consultations with a mean of 19 minutes. Contraceptive supply to first-time pill users took a mean of 21 minutes $(\mathrm{SD} \pm 3.9)$, first supplies to established pill users 20 minutes ( $\mathrm{SD} \pm 5.4$ ), subsequent supplies 17 minutes $(\mathrm{SD} \pm 3.4)$, a general referral 15 minutes $(\mathrm{SD} \pm 4.7)$ and LARC referral 13 minutes $(\mathrm{SD} \pm 3.3)$. Mean consultation time was 19, 22 and 36 minutes in Pharmacies A, B and C, respectively.

\section{Client evaluation}

Questionnaires were returned by 99 clients (total number of clients in time period $=260$; response rate $=38.1 \%)$. Most clients' consultations (84.4\%, 81/ 96) had taken place in their local pharmacy. If the service had not been available in the pharmacy, 10.6\% (10/94) would not have accessed contraception elsewhere.

Most respondents $(88.3 \%, 83 / 94)$ reported discussing LARC. Of those who completed the questionnaire, most $(87.5 \%, 84 / 96)$ were very satisfied with the service they had received, nine respondents were satisfied, none dissatisfied. Three were very dissatisfied (no further information provided). Most respondents $(96.9 \%, 94 / 96)$ reported being very comfortable or comfortable talking to the pharmacist about contraception, no client was uncomfortable, although three people were very uncomfortable. All respondents were happy about privacy. All who responded (68/72) would recommend the service.

\section{Mystery shopper evaluation}

Mystery shoppers undertook 19 visits to Pharmacies A (seven visits), B (six visits) and C (six visits), 
although not all mystery shoppers completed all the assessment questions. On 8/14 visits where the question was completed, mystery shoppers rated counter staff very helpful or helpful. This ranged from $1 / 4$ mystery shoppers in Pharmacy $\mathrm{C}$ to $5 / 5$ in Pharmacy B. No one felt uncomfortable at the counter and all were happy with privacy. Twelve of 17 visits resulted in an immediate consultation (ranging from $3 / 6$ in Pharmacy $\mathrm{C}$ to $5 / 6$ in Pharmacy A) and the remaining visits resulted in mystery shoppers having to return. Ten of 13 visits resulted in mystery shoppers being happy with the waiting time (ranging from $2 / 3$ in Pharmacy C to $5 / 5$ in Pharmacy C).

Eleven of 14 visits resulted in trained pharmacists being rated as friendly and approachable $(2 / 4$ in Pharmacy C, 4/5 in Pharmacy A and 5/5 in Pharmacy B), 13 rated pharmacists knowledgeable about the pill (3/4 in Pharmacy C, 5/5 in Pharmacies A and B), 11 rated pharmacists knowledgeable about LARC (2/4 in Pharmacy C, 4/5 in Pharmacy B and $5 / 5$ in Pharmacy A) and seven rated pharmacists knowledgeable about SRH services (ranging from $1 / 4$ in Pharmacy C to $4 / 5$ in Pharmacy A). Overall, on $14 / 16$ visits mystery shoppers were very satisfied or satisfied with the service (4/5 in Pharmacy C, 5/6 in Pharmacy $A$ and $5 / 5$ in Pharmacy B).

\section{Clinical audit}

The clinical audit concluded that of the notes audited ( $n=180,24 \%$ of total number of consultations) the pharmacists had adhered to the PGD, made clinically appropriate supplies and referred correctly in all the cases reviewed.

\section{DISCUSSION}

\section{Service provision}

This evaluation identifies community pharmacists as clinically competent to provide OC through a PGD, and pharmacies as a feasible site. The number and duration of consultations and proportion of subsequent pills supplied varied between pharmacies. This could reflect differences in staffing levels, local demographics or number of EHC consultations. In particular, it should be noted that Pharmacy A provided a much higher number of consultations than any other pharmacy. This may be because the pharmacy undertakes more EHC consultations than the other sites. The high standard deviation in mean consultation time suggests large variation. This could reflect the diversity of clients requesting contraception, the pharmacist's familiarity with the PGD or different consultation styles, and warrants further investigation.

\section{Referral}

A number of unexpected referrals were received from general practice staff and SRH services. This indicates that community pharmacy may provide contraception when other services have high demand or are unavailable, thus increasing access to contraception. However, it was not possible to determine how many clients were referred by each service.

\section{Client profile}

The aim was to provide contraception to local young women who would not otherwise access contraception, or who used EHC as their regular method of avoiding pregnancy rather than long-term contraception. Nearly half of clients (46.1\%) receiving an initial supply were first-time pill users and nearly half of consultations (45.5\%) occurred following an EHC supply, indicating that the service was accessed by the target group. It is likely that the latter proportion is actually higher, as one limitation was that referral data included subsequent consultations. Another limitation was that the data did not identify the number of times clients had used EHC, or previous contraceptive use other than OC.

The highest proportion of consultations (43.6\%) was with clients aged 20-24 years, with nearly a quarter $(22.5 \%)$ aged under 20 years. This corresponds with the ages of those women at most risk of having a termination. ${ }^{10}$ However, although this service aims to reduce teenage pregnancy, the available data only provided age by category. It would have been useful to know how many clients were 17, 18 and 19 years old respectively, in order to know how many under-18-year-olds had accessed the service. The fact that $77.5 \%$ of clients were aged 20 years and over indicates that this age group requires a service. However, they may be in danger of being overlooked under policy that often focuses on service provision for teenagers.

Most clients (97.1\%) were Southwark or Lambeth residents. Women from black African, black Caribbean, black British or other black ethnic groups were overrepresented (54.1\%) and women from white British, white Irish or other white ethnic groups underrepresented $(32.2 \%)$ compared to the local population. ${ }^{11}$ Since local conception rates are higher in black Caribbean and black African women and terminations higher in young black African women, this suggests the service is being accessed by the target population. However, available data identified number of consultations rather than number of clients, and does not allow for linking individual demographic data, for example, ethnicity with age group.

\section{Client satisfaction}

Most of the 99 clients who completed a satisfaction questionnaire were very satisfied or satisfied with the service and felt comfortable talking to the pharmacist about contraception. This was higher than other pharmacy sexual health service evaluations ${ }^{13}$ and this study does not agree with other studies where clients were unhappy about counter privacy. ${ }^{12}{ }^{13}$ However, the present findings need to be interpreted with 
caution, as they are based on only a small sub-group of the total study population. In addition, although pharmacists were asked to give questionnaires to all clients during the time period, a limitation is that it is not known if this occurred.

Most mystery shoppers would recommend the service but some experienced problems obtaining a consultation, similar to previous findings. ${ }^{13}$ Pharmacists were largely considered knowledgeable on OC and LARC, although less so on local SRH services. Pharmacy $\mathrm{C}$ was assessed less favourably by mystery shoppers than Pharmacies A and B, perhaps because the pharmacy only had one trained part-time pharmacist and could not always offer immediate consultations. It is recommended mystery shopper evaluations are repeated to evaluate any changes.

\section{CONCLUSIONS}

Trained pharmacists were clinically competent and provided OC in community pharmacy. Retention of trained pharmacists may have impacted some pharmacies' capacity to provide a consistent service. This service was accessed by the target population; young women using EHC who had not previously used OC. Client satisfaction within the service, based on selfreports from a self-selected small sub-group of clients, was very satisfactory, though this cannot be extrapolated to the entire study population or the general public. Mystery shoppers were largely satisfied, although they reported difficulties obtaining a consultation in some pharmacies.

Acknowledgements The authors would like to thank the Community Pharmacy Oral Contraceptive Pilot Group for their support and guidance, in particular Ali Young for conceptualisation and Usha Desai for evaluation and training. They would like to thank Lambeth and Southwark sexual and reproductive health services for providing clinical placements, on-call support and training, in particular Ali Kubba, Margaret Nowicki, Sarwat Bari and Uma Kulkarni, as well as Mark Ashworth at the Lister Health Centre for on-call support. The authors acknowledge the advice and support of Gary Alessio in the mystery shopper evaluation. They are grateful to the participating pharmacists for conducting the service and collecting data and the mystery shoppers for their evaluation.

Funding The work was initially funded through the Sexual Health Modernisation Initiative by Guys and St Thomas' Charity, and then by the Department of Health through NHS London. Funders were not involved in the study design, collection, analysis and interpretation of data, nor in the writing of the report.

Competing interests None.
Provenance and peer review Not commissioned; externally peer reviewed.

\section{REFERENCES}

1 Amu O, Appiah K. Teenage pregnancy in the United Kingdom: are we doing enough? Eur J Contracept Reprod Health Care 2006;11:314-318.

2 Department for Education. England Under 18 and Under 16 Conception Statistics 1998-2009. 2011. http://media.education. gov.uk/assets/files/pdf/e/england\%20under\%2018\%20and\% 20under\%2016\%20conception\%20statistics\%201998-2009\% 20feb\%202011.pdf [accessed 14 October 2011].

3 Kane R, Wellings K. Reducing the Rate of Teenage Conceptions. An International Review of the Evidence (data from Europe)Part 1. 1999. http://www.nice.org.uk/niceMedia/documents/ pregnancyinternationalpt1.pdf [accessed 14 October 2011].

4 Department for Education and Skills. Teenage Pregnancy: Accelerating the Strategy to 2010. 2006. http://media.education. gov.uk/assets/files/pdf/t/teenage $\% 20$ pregnancy $\% 20 \% 20 \%$ 20accelerating $\% 20$ the $\% 20$ strategy $\% 20$ to $\% 202010$.pdf [accessed 14 October 2011].

5 Swann C, Bowe K, McCormick G, et al. Teenage Pregnancy and Parenthood: A Review of Reviews. 2003. http://www.nice.org. uk/niceMedia/documents/teenpreg_evidence_briefing_summary. pdf [accessed 14 October 2011].

6 Department for Children, Schools and Families Publications. Teenage Pregnancy Strategy: Beyond 2010. 2010. https://www. education.gov.uk/publications/eOrderingDownload/ 00224-2010DOM-EN.pdf [accessed 14 October 2011].

7 National Institute of Clinical Excellence. Long-acting Reversible Contraception: The Effective and Appropriate Use of Long-acting Reversible Contraception. 2005. http://www.nice. org.uk/nicemedia/live/10974/29912/29912.pdf [accessed 14 October 2011].

8 Anderson C, Blenkinsopp A. Community pharmacy supply of emergency hormonal contraception: a structured literature review of international evidence. Hum Reprod 2006;21:272-284.

9 Raymond EG, Trussel J, Polis CB. Population effect of increase access to emergency contraceptive pills: a systematic review. Obstet Gynecol 2007;109:181-188.

10 Petrie S, Jawad R, Bhatti S. Southwark Young People's Sexual Health \& Teenage Pregnancy Needs Assessment \& Equity Audit: Final Report. 2006. http://www.southwarkpct.nhs.uk/ documents/4660.pdf [accessed 14 October 2011].

11 Office of National Statistics. Resident Population Estimates by Ethnic Group, Females (2001-2009). 2011. http://www. neighbourhood.statistics.gov.uk/dissemination/LeadTableView. do $? \mathrm{a}=3 \& \mathrm{~b}=276770 \& \mathrm{c}=$ southwark $\& \mathrm{~d}=13 \& \mathrm{e}=13 \& \mathrm{~g}=$ $345022 \& \mathrm{i}=1001 \times 1003 \times 1004 \& \mathrm{~m}=0 \& \mathrm{rr}=1 \& \mathrm{~s}=$ $1324293242422 \&$ enc $=1 \&$ ds FamilyId $=1811$ [accessed 14 October 2011].

12 Black KI, Mercer CH, Kubba A, et al. Provision of emergency contraception: a pilot study comparing access through pharmacies and clinical settings. Contraception 2008;77:181-185.

13 Baraitser P, Pearce V, Holmes J, et al. Chlamydia testing in community pharmacies: evaluation of a feasibility pilot in south east London. Qual Saf Health Care 2007;16:303-307.

14 Baraitser P, Clough L, Cooper R, et al. Mystery Shopping in Sexual Health: A Toolkit for Delivery. 2008. http://www. gsttcharity.org.uk/pdfs/mystery.pdf [accessed 14 October 2011]. 